\title{
on the right track
}

\author{
Vivienne Baillie Gerritsen
}

Left only to the passage of time, everything gravitates towards chaos. Gardens become overgrown. Roads gather potholes and cracks. Relationships wither, and teeth rot. We have ways of dealing with this however. Gardeners look after the lawns, engineers inspect the roads, therapists have a go at unravelling relationships, and dentists tend to our mouths. Life, too, has its keepers. Left unattended, the very essence of life - our DNA - will collect unfortunate mutations that have the power to wreak havoc inside us. Over time, our cells have found ways of coping with this by promoting, for example, self-destruction so as not to propagate what has become unhealthy, or by repairing damaged DNA. As a result, cells are kept on the right track. Who, though, is the keeper? Different keepers are summoned at different stages and depending on the cell's fate. One protein, however, seems to be the orchestrator. Its name is $\mathbf{p 5 3}$, and it has been studied extensively since the 1970 s because when it goes wrong, life is at stake.

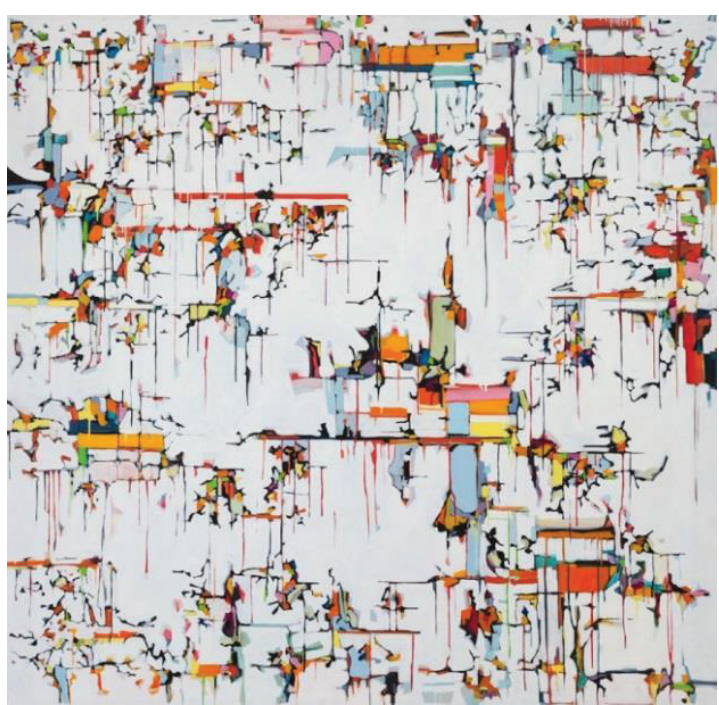

"Poetic Faith", by Glynis C. Tinglof

Courtesy of the artist

p53 is one of the most studied proteins ever because it is at the heart of many forms of one the most widespread diseases in human beings: cancer. In the early 1970s, a link between p53 and the formation of tumours had already been acknowledged but the viral origin of cancer was still a popular assumption among researchers. By the late 1970s, however, it became apparent that $\mathrm{p} 53$ was not a viral protein that had been injected into its host but rather a protein that belonged to the host itself. Though some forms of cancer are indeed caused by viruses, this particular discovery shifted the attention of scientists to the insides of humans as opposed to those of viruses. Research on p53 plodded on until the late 1980s when it literally exploded. This is because p53's role in vital activities such as cell growth and survival had been unveiled, as had its crucial involvement in DNA repair. p53 is central in spotting DNA that has been spoiled, and setting off pathways that will fix the damage. It is because of this protective role that $\mathrm{p} 53$ is sometimes referred to as "the guardian of the genome".

Though, paradoxically perhaps, life and evolution depend on changes that occur in DNA, some parts are best left untouched. This is no doubt why Nature designed a protein such as p53. One of p53's major roles is to protect the integrity of the genome, i.e. to fix damaged DNA that may well cause downstream harm. When DNA needs fixing, cell growth is temporarily interrupted while p53 calls for repair. If the damage is too bad, the cell will either be kept in this arrested - and harmless - state (senescence), or it will be prompted to commit suicide (apoptosis). This can be compared to a broken-down car that has been taken off the road a few days while a mechanic attends to it. If the car is beyond repair, there are chances it will be set aside in a remote corner of the garage or taken away for demolition.

In the recent past however, researchers discovered that $\mathrm{p} 53$ is also involved in other less life-threatening circumstances, such as cell homeostasis, tissue growth, the nestling of the blastocyst in the uterus and 
old age. However, whichever way you look at it, p53 certainly seems to be central to what keeps life going, so its own regulation and activation have to be exquisitely tuned. Too much p53, and tissue growth or longevity could be touched. Not enough of it, and tumours may emerge or cells be requested to die unnecessarily. p53 must be activated at the correct time - when metabolic homeostasis is threatened, for example, or DNA is damaged. Stress signals, such as the lack of nutrients or irradiation, upregulate the synthesis of p53, while hordes of transcriptional and post-transcriptional modifications like acetylation, phosphorylation, ubiquitination and glycosylation modulate p53 stability and activity. Recently, scientists discovered that micro RNAs (miRNAs) also seemed to have an effect on p53 activity.

So what does p53 do exactly? p53 is a nuclear transcription factor whose active site has one $\mathrm{Zn}$ atom. Once called in for action, tetrameric p53 regulates the expression of various genes by binding to their promoters. The products of these genes then relay signals to set off metabolisms whose ultimate job is to repair damaged DNA, plunge a cell into senescence, promote cell death or assist tissue growth, cell homeostasis and longevity. It is not difficult to grasp that if p53 is dysfunctional, many important processes in a cell are hindered. In particular, cells are left to proliferate unimpeded and their DNA to accumulate mutations - which are the fodder of cancer. This is why p53 is known as a tumour suppressor, which is perhaps an anthropocentric way of saying that when p53 is healthy, it keeps an eye on the state of our DNA and makes sure cell division is normal.

What, do life scientists define as "cancer"? To cut a very complex and long story short, cancer is caused by cells that belong to us and have acquired the unfortunate faculty of multiplying in an uncontrolled manner. If the unchecked growth begins in the lungs, it causes lung cancer. If it emerges in the breast, it causes breast cancer. This unrestrained growth creates tumours - or clumps of cells - that can shed smaller tumours, or metastases, which find ways of entering the blood stream or the lymph system to invade other parts of our body where they will also grow unceasingly. At the same time, tumours gradually acquire a life of their own by stimulating the growth of tiny blood vessels that provide nutrients to keep them "alive". Tumours become harmful to an organism because they begin to hinder the organs in which they are growing. If the organs are vital - such as our lungs, our kidneys, our liver or our brain - our life is at risk.

p53 was elected molecule of the year in the December issue of Science in 1993. Exactly 25 years ago. The tumour suppressor activity of p53 and hence its capacity to become oncogenic once mutated lending it a Jekyll and Hyde nature - was then a novelty. A quarter of a century on, though far more is known on the molecular level, cancer still continues to kill many people around the globe. If doctors were able to check the malfunction of mutated p53 in patients, or pump functional p53 into them, would this not be a way of treating - or at least - slowing down the progression of cancer? Perhaps, yes. The fact is, mutated p53 is found in only $50 \%$ of all tumours. What is more, dysfunctional p53 is modified in different ways, which makes it all the more difficult for drugs to target. Nonetheless, there is great hope for p53 personalised therapeutics in the years to come. Thousands of years ago, human beings lived to the average age of 30 , which would not have given p53 the opportunities it has today to become dysfunctional. We seem to be standing on a curious set of scales where, on one side, we have created conditions that make life longer and, on the other, we are forging an environment whose tendency is to make it shorter.

\section{Cross-references to UniProt}

Cellular tumor antigen p53, Homo sapiens (Human): P04637

\section{References}

1. Farnebo M., Bykov V.J.N., Wiman K.G.

The p53 tumor suppressor: A master regulator of diverse cellular processes and therapeutic target in cancer Biochemical and Biophysical Research Communications 396:85-89(2010)

PMID: 20494116

2. Soussi T.

The history of p53 - a perfect example of the drawbacks of scientific paradigms

EMBO Reports 11:822-826(2010)

PMID: 20930848

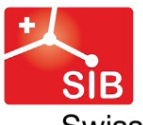

\section{proteinspotlight}

Protein Spotlight (ISSN 1424-4721) is a montly review written by the Swiss-Prot team of the SIB Swiss Institute Swiss Institute of of Bioinformatics. Spotlight articles describe a specific protein or family of proteins on an informal tone. Bioinformatics http://web.expasy.org/spotlight/ 